The BDJ News section accepts items that include general news, latest research and diary events that interest our readers. Press releases or articles may be edited, and should include a colour photograph if possible. Please direct your correspondence to the News Editor, Arveen Bajaj at the BDJ, 64 Wimpole Street WIG 8YS or by e-mail to bdj@bda.org

\section{GDC to seek rise in ARF fees}

The GDC recently agreed to seek new annual retention fee (ARF) levels at its meeting in June. For dentists, the fee sought will be $£ 388$ for 2004 and $£ 439$ for 2005.

The fee sought for dental hygienists and therapists will be $£ 68$ for 2004 and $£ 75$ for 2005. The Council also decided that the current fee paid by two classes of specialists - oral surgeons and orthodontists - to be retained on the Specialists Lists, should be abolished for the time being.

It will decide whether and what amount all specialists should be charged when the law has been amended to allow it to charge all categories of specialist. The GDC is set to discuss fee levels with the $\mathrm{DoH}$ with a view to submitting proposals to the Privy Council as soon as possible.

It claims that the increase in the fees would enable it to meet demands placed on its existing functions and implement its reform programme.

In a statement, GDC president Hew Mathewson admitted that the increase in the ARF was significant but asserted that it was essential if the GDC was to progress modernisation of the regulation of dentistry and become a more efficient regulator.

\section{Professional conduct cases heard}

The GDC Professional Conduct Committee met for ten days at the beginning of June and heard five cases.

Alexander Eugen Durr was found guilty of serious professional misconduct and admonished while Kevin Fletcher and Michael Sudak Rajan were found guilty of serious professional misconduct and erased.

Mohammad Daud Toukhi was found not guilty of serious professional misconduct and Peter Coffey's case was adjourned until 31 July. The committee will next meet between 7 and 18 July.

\section{Screening athletes for healthy teeth}

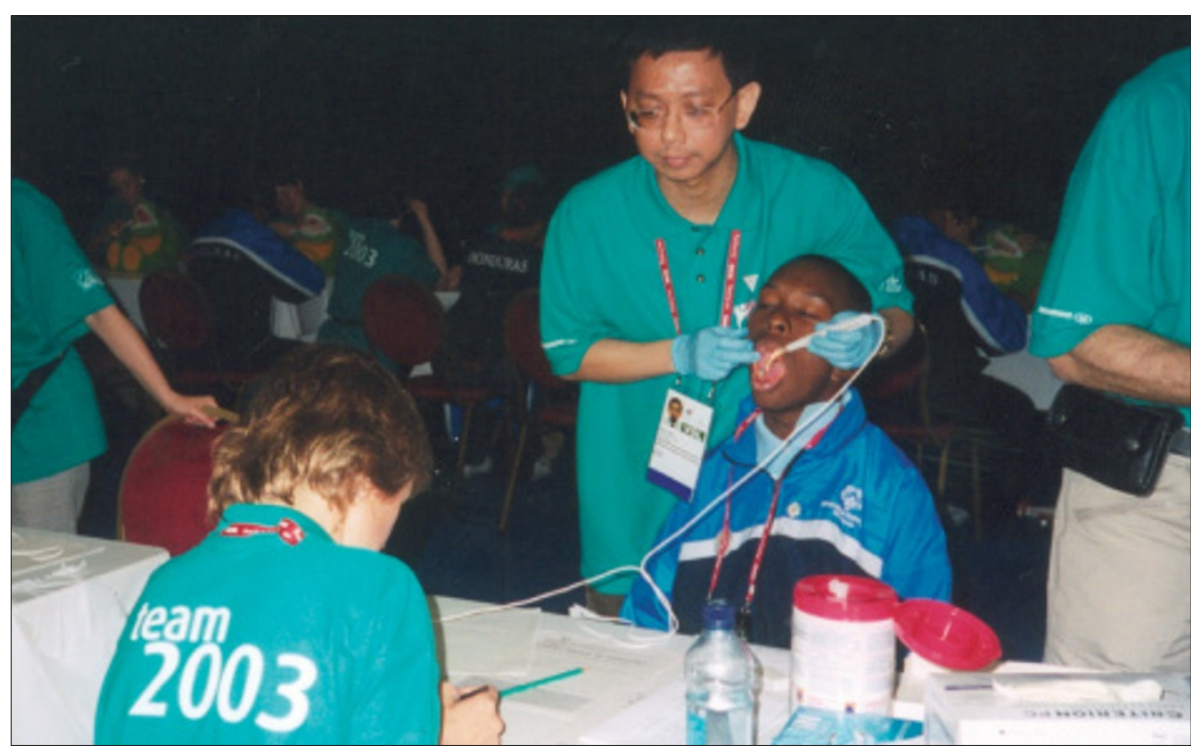

Numerous dental volunteers from over 15 countries screened approximately 3000 athletes at the recent Special Olympics World Summer Games in Ireland. Special Olympics is the worldwide sports movement for people with learning disabilities and the games is its flagship event, taking place every four years. As well as dentistry, athletes were invited for screening in areas including optometry, audiology and podiatry. (Above, volunteer dentist Albert Yeung, a clinical lecturer in dental public health from the University of Manchester, carries out a standardised oral health screening for an athlete from Honduras, Central America)

\section{Lords backs fluoridation proposals}

Peers in the House of Lords backed a move towards water fluoridation by 153 to 31 .

The move would involve an amendment to the water bill that would force water boards to add fluoride to water supplies provided local health authorities consulted with local people and found support for it.

The BDA has campaigned for water fluoridation and though water companies do currently have the power to fluoridate water, they have not done so because of fear of legal action from those who oppose it. The new move will shift the decision to local authorities and communities.

Around five million people in the UK already have fluoridated water in areas such as the West Midlands, as do two per cent of people in Ireland and around 150 million people in the US.

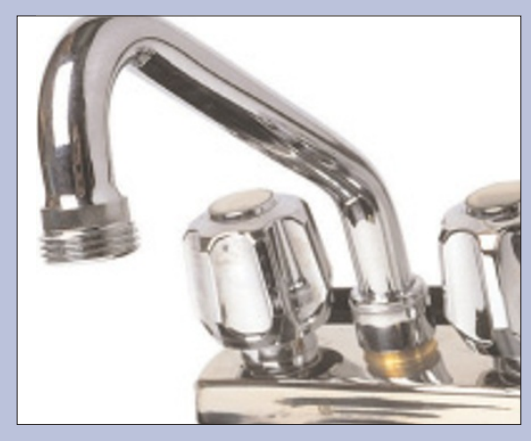

However, countries such as France, Italy, Sweden and the Netherlands have rejected it.

The Department of Health is currently funding research into the effects of exposure to naturally fluoridated and artificially fluoridated drinking water and will report its findings later this year. The bill will have a second reading this September. 


\section{NEWS IN BRIEF}

\section{New Eastman programme launched}

The Eastman Dental Institute is set to offer a new one year programme leading to a newly established University Diploma in Clinical Dental Science, from October this year. It is designed to meet the needs of overseas graduates who wish to extend their dental education in the UK but who need a period of further study before commencing specialist training. It has both clinical and taught components and is recognised as equivalent to the year of approved experience required for entry into the MFDS examination.

\section{Australian UCH reunion}

A reunion of University College Hospital (UCH) graduates has been planned at the FDI in Sydney Australia later this year as a large number of former UCH students have moved to Australia. Any UCH graduates who are planning to go to the FDI and would like to attend the reunion should contact phill@doh.health.nsw.gov.au.

\section{Distinguished professor \\ honoured}

The Eastman Dental Institute will be hosting a half day symposium in honour of Professor Roderick Cawson on September 13. The co-author of Essentials of Dental Surgery and Pathology and Medical Problems in Dentistry is currently emeritus professor at the Eastman. His career has been mainly in the fields of oral pathology and oral medicine and the half day will include presentations from many colleagues from the UK and overseas followed by a reception.

\section{First female Dean appointed}

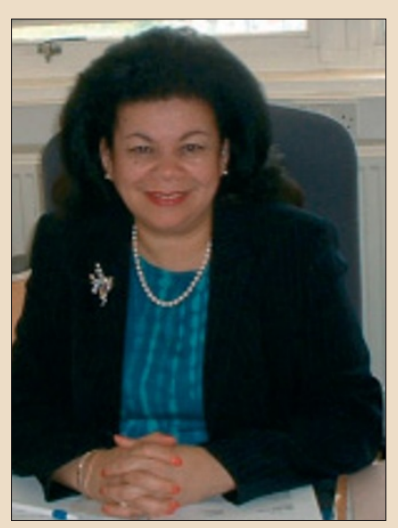

The UK's first ever female Dean of Dental Studies has been appointed at the University of Liverpool. Professor Cynthia Pine took up the position on 1 August, which is a first for the dental profession. Since the first dental school opened in 1859 there has never been a female Dean of a Dental School, until now.

Professor Pine graduated in dentistry from the University of Manchester in 1976 and completed her $\mathrm{PhD}$ there in 1982. In 2001 she gained her MBA from the University of Dundee and was a professor at Dundee before joining the University of Liverpool in 2002 as professor of dental public health and primary dental care. She became director of the World Health Organisation Centre for Oral Health in Deprived CommuniProfessor Cynthia Pine ties earlier this year and is also honourary professor at the University of Dundee.

\section{The wrong trousers}

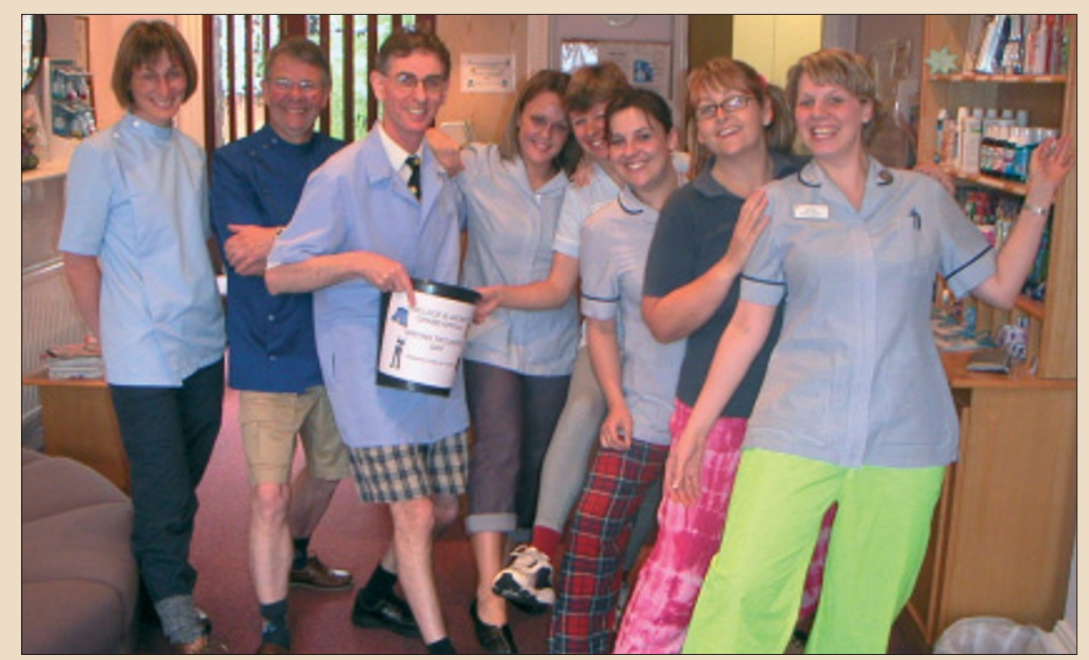

Oakdale Dental Practice in Leicester recently took part in Wallace and Grommit's Wrong Trousers Day to raise money for the children's hospital at the Royal Infirmary in Leicester. The team raised the cash from donations from staff and patients at the practice. 


\section{Practice's success recognised}

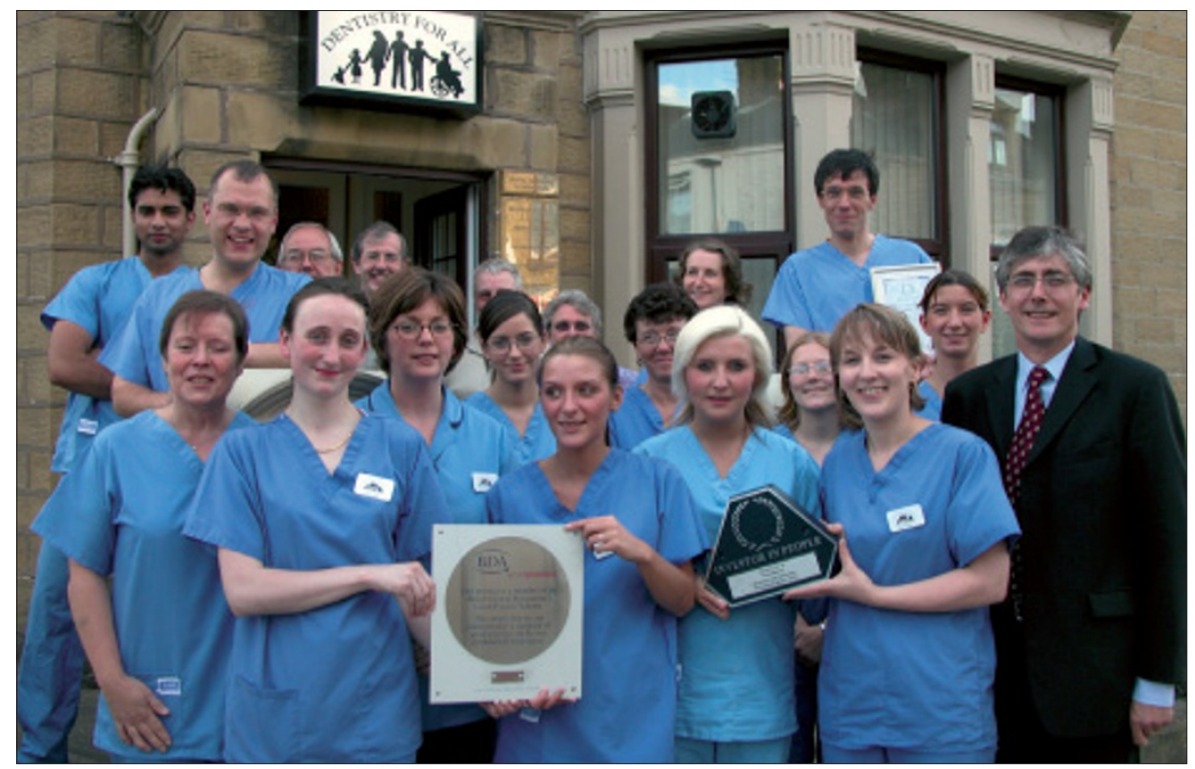

Dentistry For All dental practice in Nelson, Lancashire has become one of only a handful of dental practices in the country to be accredited to the BDA Good Practice Scheme as well as being recognised as an Investor in People. The six-surgery practice works predominantly within the NHS.

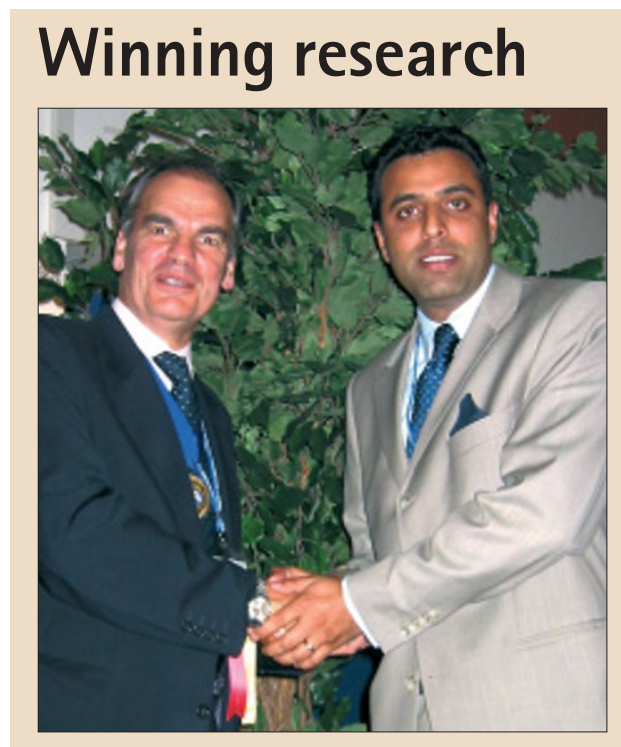

Shakeel Shahdad (right) is awarded the BSDR Ivoclar Prize for Research in Dental Biomaterials Sciences by Professor David Williams at the IADR meeting, Gothenburg.

Dr Shahdad was awarded the prize for his work on the wear of denture teeth when used in implant retained prostheses. This work is being carried out as part of his specialist training programme in restorative dentistry and is being sponsored by NHS Executive Research and Development, Newcastle upon Tyne Hospitals Special Trustees and Ivoclar Vivadent.

\section{Life after surgery}

Corsham dentist Tom Fox recently ran the 2003 Paris Marathon finishing in a time of four hours 12 minutes.

Less than two years ago he had undergone surgery for five coronary artery bypasses. Cardio-thoracic surgeon Franco Ciulli based at the Bristol Royal Infirmary used the pioneering technique of operating on the beating heart rather than using the more usual support of a heart-lung machine. Showing that there is life after heart surgery, Dr Fox also hopes to take part in next year's London Marathon where he aims to break the four hour barrier.

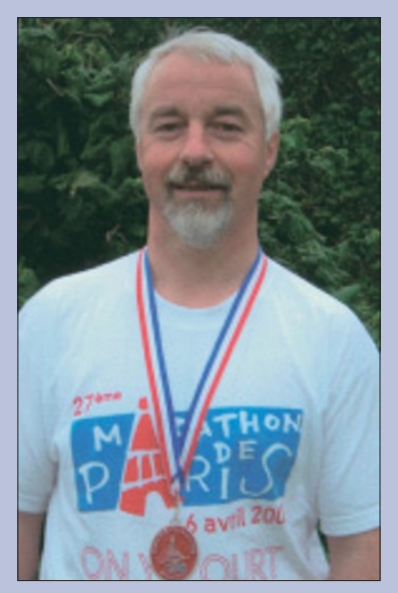

